\title{
Textiles tradicionales de la Puna Atacameña
}

\begin{abstract}
RESUMEN
El presente trabajo expone antecedentes reunidos en el transcurso del proyecto "Textiles atacameños: Investigación, registro y diagnóstico de las artesanías textiles del Loa y el Salar de Atacama" ${ }^{3}$ realizado durante el año 2000. Este ha permitido actualizar información sobre la situación de las tradiciones textiles en la zona, verificando su pervivencia y al mismo tiempo su frágil subsistencia.

Se da cuenta de la gran variedad de prendas que se conservan en los hogares atacameños y las diversas funciones que cumplen en su vida cotidiana. Se intenta sintetizar sus características técnicas y visuales, describiendo en algunos casos las distintas tipologías.
\end{abstract}

Palabras claves: Técnicas textiles - textiles etnográficos Atacama.

\section{ABSTRACT}

This work displays data gathered during the project "Textiles of Atacama: Research, record and diagnosis of the textile handcrafts from the Loa river and the Salar of Atacama", carried out during the year 2000. The research has allowed to update information about the situation of textile traditions in the area, verifying its persistence and at the same time, its fragile subsistence.

The paper provides an outlook of the great variety of garments preserved in the Atacama homes and the diversity of functions they perform in daily life. It is aimed to synthesize its technical and visual characteristics, describing in some cases the different typologies.

Key words: Textile techniques - ethnographic textiles Atacama.

\section{Introducción}

Los textiles tradicionales de la zona de Atacama son herederos de culturas locales ancestrales y de

1 Escuela de Diseño, Pontificia Universidad Católica de Chile. Email: shoces@directo.cl

2 Comité Nacional de Conservación Textil. Email: amroj@directo.cl

3 Proyecto financiado por Fundación Minera Escondida y CONADI.
Soledad Hoces de la Guardia Ch. ${ }^{1}$ y Ana María Rojas Z. ${ }^{2}$

distintas influencias foráneas a través de los siglos. Estas provienen del Noroeste argentino, del altiplano chileno-boliviano y de Europa, a partir de la conquista. En el último siglo se han incorporado otras técnicas y diseños más contemporáneos y de carácter urbano.

Nuestra inquietud por el conocimiento del textil atacameño de hoy surge naturalmente, luego de investigar textiles arqueológicos de la zona y preguntarnos qué había ocurrido con esa tradición. Durante esas exploraciones de trabajo, buscamos ansiosamente los textiles actuales, que son escasos en el comercio y difíciles de hallar bajo tanta oferta de tejidos provenientes de Bolivia o Perú. Eso nos llevó a seguir indagando, revisar los estudios que se habían hecho en ese aspecto, y luego plantearnos la actualización de la información que hasta ese momento indicaba que prácticamente ya no quedaban tejedores en Atacama.

Los primeros estudios publicados que hacen referencia directa a los textiles etnográficos en la zona de Atacama, pertenecen a Grete Mostny (1954). Aunque estos se refieren específicamente a investigaciones realizadas entonces en el pueblo de Peine, la precisión de los datos registrados nos permiten hoy día identificar y corroborar los rasgos de la textilería atacameña que aún se conservan y también aquellos que se han ido perdiendo. Es interesante comprobar cómo las tradiciones textiles estudiadas por Mostny en los años '50, ya en ese entonces parecían en peligro de desaparecer, si bien aún perduran, pero más aisladamente y con modificaciones. De todas las artesanías locales, el tejido, aunque debilitado, es el de mayor presencia y que más claramente conserva patrones tradicionales.

Particular importancia reviste el trabajo desarrollado por Ingeborg Lindberg (1967), producto de varios años de realizar registros de campo, en los que tuvo especial preocupación por los tejidos. Además de los datos sobre costumbres, técnicas, prendas y nomenclatura textil, es hasta este momento el único estudio que intenta dejar un regis- 
tro gráfico sobre los diseños. Es en este sentido en el que se han orientado y definido algunos aspectos de nuestra búsqueda. Como profesionales formadas en las áreas del arte y el diseño nos hemos preocupado particularmente de realizar un acucioso registro fotográfico y posteriormente ir procesando este material con dibujos para dejar constancia en textos e imágenes de las características de los textiles de Atacama.

Al comprobar la progresiva extinción de los modos de nombrar, programar y tejer los textiles, nos preocupa que de la misma manera se vayan perdiendo colores, modos de componer el espacio del tejido, construir formas y figuras, y como resultado perder definitivamente el lenguaje de esos textiles. Así como estamos reconstruyendo a partir de publicaciones que a la fecha tienen 35 años o más, consideramos urgente todos los esfuerzos que se puedan realizar para que lo que publicamos hoy permita revivir o conservar en la memoria de los atacameños sus tradiciones textiles. Que no tengamos que lamentar otra pérdida total en el mundo andino como ocurrió con la lengua kunza que un día no se oyó más.

La investigadora Lindberg, que entonces formaba parte del Departamento de Antropología de la Universidad del Norte, fue llamada por el Ministerio de Agricultura para realizar un trabajo de registro y reactivación de la industria textil, en el que se desarrollaron nuevos productos. Este se enlazó con el llamado "Plan Cordillera", propiciado por la Iglesia Católica y la Fundación Cáritas-Chile, dentro del cual se desarrollaron otros proyectos, entre ellos: piedra volcánica en Toconao (1963-66) y en alfombras (1974), en el que participaron artesanos de Socaire, Camar y Talabre. La antropóloga termina el citado artículo con la siguiente reflexión:

“Es de esperar que en algunos años más veremos en todo el Norte Grande de Chile industrias caseras muy desarrolladas sobre las que vigilaremos que no sufran alteraciones ni falsificaciones debido a influencias ajenas a su propia tradición”.

Y a la vuelta de estos años nos encontramos aún realizando esfuerzos similares...

Más tarde, a fines de los años '70, monitores de CEMA-Chile introdujeron en el sector del Loa Medio una artesanía de paños bordados en lanas de vivos colores. Posteriormente en 1992 se rea- lizan en comunidades de la misma zona otras capacitaciones financiadas por Fundación Andes, en bordado y tejido a telar de lizos.

Algunos de estos proyectos han logrado prosperar en el tiempo y, aunque aisladamente, hay quienes siguen produciendo artesanías con fines comerciales; sin embargo, de lo que hemos podido observar y con la perspectiva de los años, pocas veces se ha tenido real consideración respecto de lo que a los artesanos les interesa o mejor dicho "identifica", al momento de proponer innovaciones técnicas o de productos.

En el marco de los distintos trabajos que documentan la actividad artesanal en Atacama, en el último medio siglo, no podemos dejar de mencionar los detallados estudios de Harold Krusell (1976), quien consigna datos precisos de los pueblos del Salar en un diagnóstico de las artesanías y catastro de artesanos de esos pueblos. Posteriormente se publicó el trabajo de Horacio Larraín (1990), que da cuenta de una exhaustiva investigación antropológica clasificando tipos de artesanías y sus características, recursos naturales y recursos humanos. Desgraciadamente, estos esfuerzos no han tenido el eco necesario para ser aprovechados a tiempo, ya que a pesar de ser un importante capital de información cualquier acción hoy día requiere necesariamente actualizar datos.

Es urgente realizar gestiones para registrar y preservar el patrimonio que aún se conserva. Nos referimos no sólo a la existencia de objetos textiles, sino a las tradiciones, aquellas que hablan del conocimiento, de un saber hacer, de lo que estos objetos significan y de cómo en gran medida sostienen la cultura atacameña.

\section{El proyecto}

La actividad fundamental de nuestro proyecto consistió en visitas a terreno recorriendo casa a casa. En este recorrido constatamos la presencia y práctica del tejido, pudiendo, aunque brevemente, entrevistar a artesanas y artesanos e indagar sobre la proveniencia de sus materias primas, modos de aprendizaje y prácticas actuales.

Fue sorprendente ir descubriendo en cada paso que el textil aún conserva el sitial que tradicionalmente tuvo. Eso, porque al solicitar si podían compartir los tejidos con nosotros, aparecían poco a poco prendas y objetos que conformaban parte 
del patrimonio familiar. Textiles que son atesorados con cariño, guardados como herencia o que son usados sólo en determinadas ocasiones.

Revelaciones sobre las dificultades para criar sus animales por la carencia de agua, que las labores domésticas, el pastoreo y la agricultura, cada vez dejan menos tiempo para el telar. Más aún cuando los jóvenes ya no están para contribuir en esas tareas, ya que la mayoría ha emigrado a estudiar a los pueblos más grandes o a las ciudades.

Se realizaron dos recorridos según dos áreas definidas por su geografía y su ocupación. Primero se visitó el sector cordillerano cercano al Salar y posteriormente el sector medio del valle del Loa (Figura 1).

El trabajo en terreno fue complementado por la consulta de las colecciones etnográficas de los museos de la zona, los que, con mucha visión de futuro, han rescatado parte de este patrimonio. Poseen colecciones etnográficas atacameñas de importancia los siguientes museos:

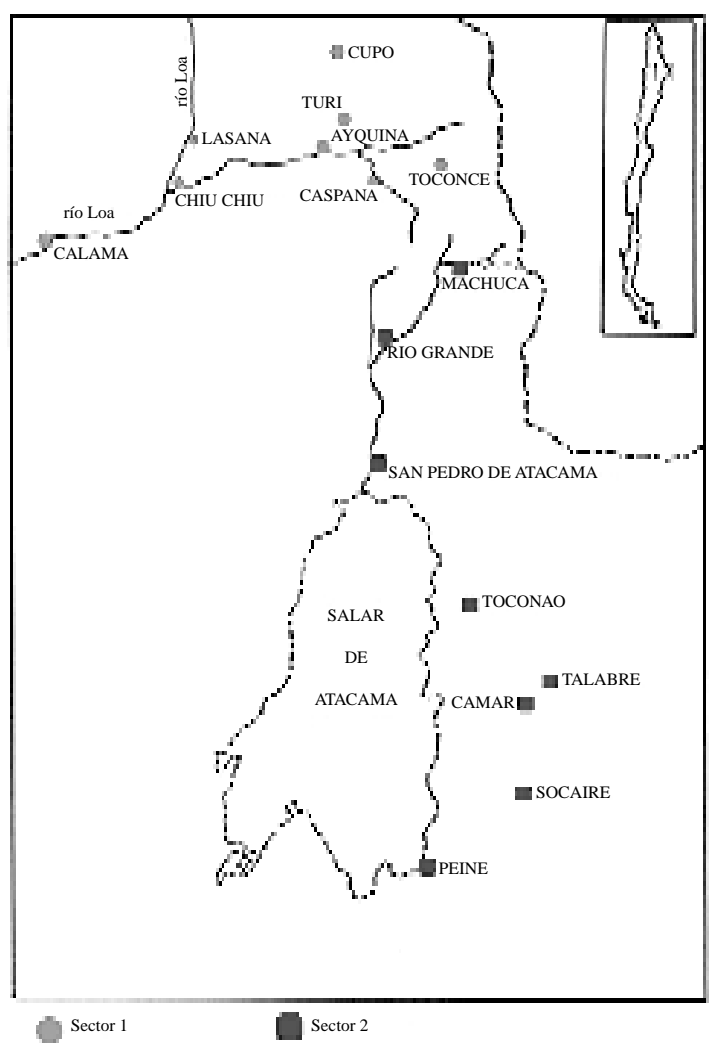

Figura 1. Lugares visitados: Sector 1 del río Loa, Sector 2 del Salar.
- Museo R. P. Gustavo Le Paige s. j., San Pedro de Atacama

- Instituto de Investigaciones Antropológicas de la Universidad de Antofagasta

- Museo Regional de Antofagasta

- Museo Municipal Parque El Loa de Calama

- Museo de Caspana.

\section{Tradiciones textiles}

Reiterando las observaciones realizadas por otros investigadores se mantiene la vigencia, desde tiempos prehispánicos y prácticamente sin alteraciones, de algunas técnicas como trenzados (Figura 2), cordones, técnicas de urdimbre en las prendas de uso doméstico, como es el caso de chuspas, talegas y costales. Lo mismo ocurre con el instrumental utilizado para hilar como el huso y la mismina o para tejer como la vinasa, tijnes o wichuñas (Figura 3).

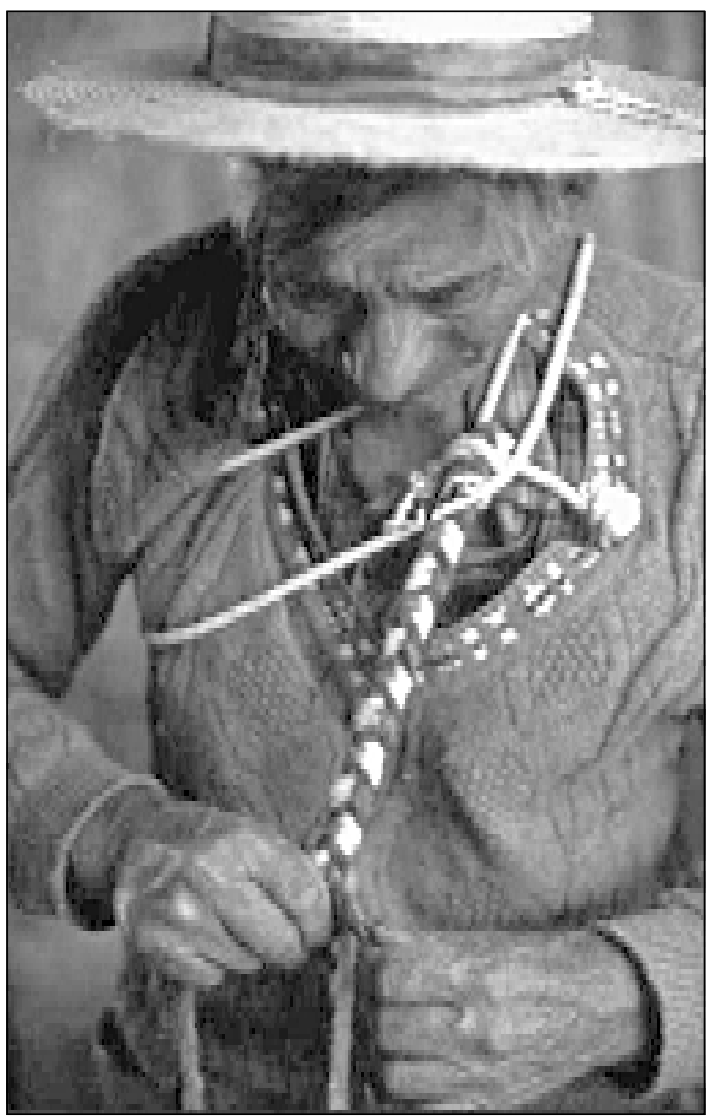

Figura 2. Fabio Soza de Talabre, trenzando soga. 


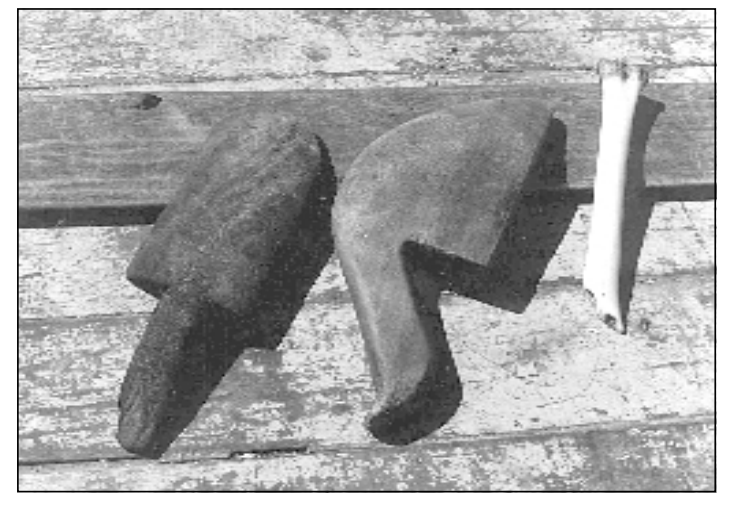

Figura 3. Instrumentos, vinasa, tijnes para faja y poncho y wichuña.

Los telares precolombinos que se siguen empleando son: el de cintura, el de suelo o awana, de cuatro estacas y distintos tamaños según la prenda (Figura 4), y se teje también en telar de lizos o español. Otros instrumentales incorporados son la rueca y los palillos o agujetas. Uno de los aspectos sobresalientes de la continuidad de las tradiciones tiene que ver con los patrones formales de las prendas, los motivos o labores dibujados en

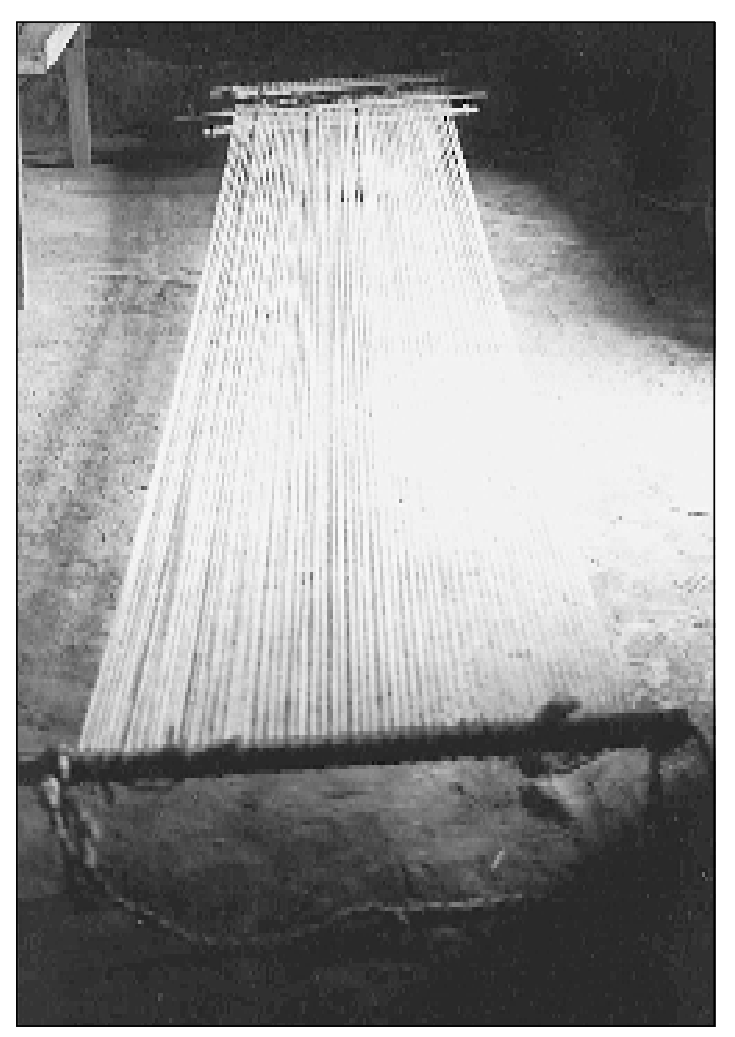

Figura 4. Telar de suelo o awana de Delfina Escalier en Toconce, dispuesto para tejer frazada. ellos y los tratamientos táctiles y visuales, producto del modo de usar los hilados, paleta de colores y sistemas de composición.

En cuanto a la persistencia de algunas soluciones formales y de composición es sorprendente el caso de los contenedores, costales, talegas y chuspas, los que conservan una fuerte tradición. Esto nos habla de soportes que han trascendido cientos de años comprobando su eficiencia tanto en las funciones de uso así como instrumentos de comunicación de contenidos culturales. Llijllas e inkuñas también tienen clara relación con piezas precolombinas.

Pero aún más sorprendente resulta comprobar cómo los patrones de diseño en las fajas, por ejemplo, siguen reglas muy similares a sus iguales prehispánicas (Figuras 5 y 6; ver en anexo gráfico Figura 7). Observar que los tratamientos de dibujo en las fajas son muy distintos a los usados en las labores de llijllas y chuspas (ver en anexo gráfico, Figuras 8, 9, 10 y 11), los que también tienen claros antecedentes en piezas arqueológicas.

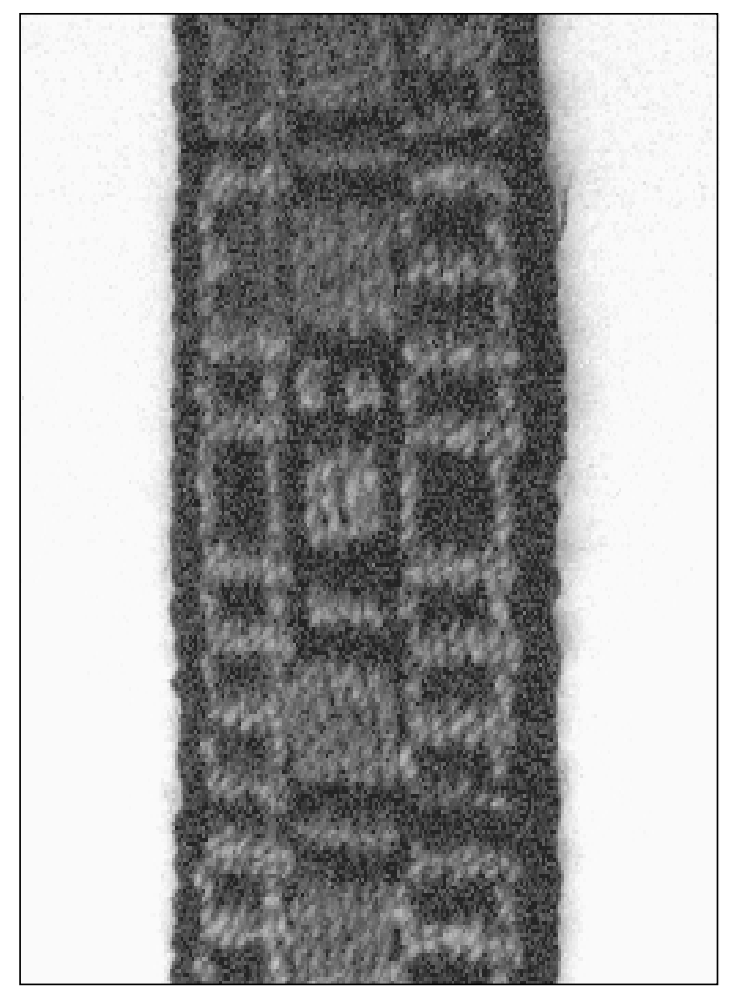

Figura 5. Faja arqueológica. 


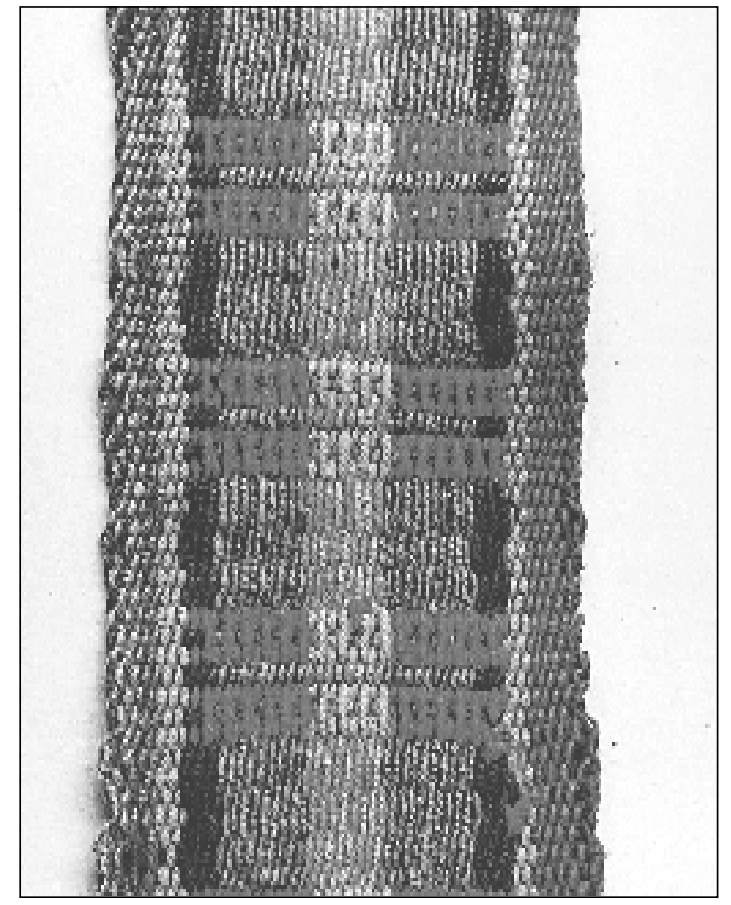

Figura 6. Faja etnográfica de Camar.

\section{Objetos textiles}

Se expone el registro de las distintas expresiones que aún se conservan de los textiles tradicionales atacameños, a partir del estudio de 506 textiles, de los cuales 277 fueron vistos en terreno y 227 pertenecen a colecciones de museos o privadas. Según su forma de uso, los textiles se pueden agrupar de la siguiente manera:

Objetos de uso cotidiano: Sogas, hondas, costales, mantas, frazadas, peleros, fajas, llijllas, paños bordados, ponchos, talegas, atapolleras.

Objetos de uso cotidiano y ritual: llijllas, paños bordados, fajas, hondas.

Objetos de uso ritual: llijllas, guatacuna, signo, chuspas, inkuña, tikallijlla.

Objetos para la comercialización: frazadas, bajadas de cama, atapolleras, hondas, sogas, chales, bolsos, calcetines, guantes, gorros, bufandas, llamitos, monederos.

Tipos de telares, prendas, estructura y color

Los cuadros 1 y 2 dan cuenta de parte del universo que abarca el textil atacameño al día de hoy, relacionando el instrumento en que fueron tejidos, la estructura resultante, la técnica que genera el color y la procedencia de éste.

\begin{tabular}{|l|l|l|l|l|l|l|l|l|l|}
\hline \multirow{2}{*}{ PRENDA } & \multicolumn{5}{|c|}{ TELARES } & \multicolumn{5}{c|}{ ESTRUCTURA } \\
\hline & CINTURA & SUELO & PEDALES & BASTIDOR & PLANO & FAZ DE U. & FAZ DE T. & SARGA & TORZAL \\
\hline Faja & & & & & & & & & \\
\hline Chuspa & & & & & & & & & \\
\hline Talega & & & & & & & & & \\
\hline Alforja & & & & & & & & & \\
\hline Costal & & & & & & & & & \\
\hline Inkuña & & & & & & & & & \\
\hline Llijlla & & & & & & & & & \\
\hline Poncho & & & & & & & & & \\
\hline Manta & & & & & & & & & \\
\hline Frazada & & & & & & & & & \\
\hline Corte & & & & & & & & & \\
\hline Pelero & & & & & & & & & \\
\hline
\end{tabular}

Cuadro 1. Relación entre las prendas, el tipo de telar empleado y las técnicas usadas. 


\begin{tabular}{|c|c|c|c|c|c|c|c|c|}
\hline \multirow{2}{*}{ PRENDA } & \multicolumn{4}{|c|}{ TELARES } & \multicolumn{4}{|c|}{ COLOR } \\
\hline & CINTURA & SUELO & PEDALES & BASTIDOR & POR URD & POR TRAMA & NATURAL & TEÑIDO \\
\hline \multicolumn{9}{|l|}{ Faja } \\
\hline \multicolumn{9}{|l|}{ Chuspa } \\
\hline \multicolumn{9}{|l|}{ Talega } \\
\hline \multicolumn{9}{|l|}{ Alforja } \\
\hline \multicolumn{9}{|l|}{ Costal } \\
\hline \multicolumn{9}{|l|}{ Inkuña } \\
\hline \multicolumn{9}{|l|}{ Llijlla } \\
\hline \multicolumn{9}{|l|}{ Poncho } \\
\hline \multicolumn{9}{|l|}{ Manta } \\
\hline \multicolumn{9}{|l|}{ Frazada } \\
\hline \multicolumn{9}{|l|}{ Corte } \\
\hline Pelero & & & & & & & & \\
\hline
\end{tabular}

Cuadro 2. Relación entre las prendas, tipo de telar empleado, técnica que genera el color y su procedencia.

\section{Catálogo de los diferentes textiles registrados}

A continuación se presenta a modo de catálogo una selección de los objetos textiles, que a nuestro parecer son más representativos de las tradiciones atacameñas, por lo que se han privilegiado aquellas tejidas a telar, considerando que son precisamente ésas las que conservan los rasgos de identidad del textil atacameño. Se incluyen como excepciones las bajadas de cama y los paños bordados, que aunque se trata de introducciones relativamente recientes, han sido incorporados y aceptados por las comunidades. Se han excluido los tejidos realizados con agujetas o palillos, porque a pesar de gozar de popularidad, los objetos que producen no tienen rasgos específicos. La presentación pretende dar una información básica de las características de uso, formales y técnicas de las piezas. Esta visión se complementa con un anexo gráfico que permite apreciar algunos aspectos técnicos y de dibujo con mayor detalle.

\section{Chuspa}

Bolsa pequeña de aprox. 11 x $13 \mathrm{~cm}$ tejida en faz de urdimbre y que se caracteriza por su elaborado diseño de listas en colores y distintos tipos de "labor". En la parte inferior de la bolsa lleva variadas formas de pompones o borlas. Las chuspas más antiguas tienen cuatro orillas, pero hoy se están haciendo seriadas, cortando la urdimbre. Sus bordes son rematados con aokipao, terminación tejida con aguja que cubre las costuras y adorna. Actualmente también se emplea en su confección lana industrial. Se mantiene su función ritual.

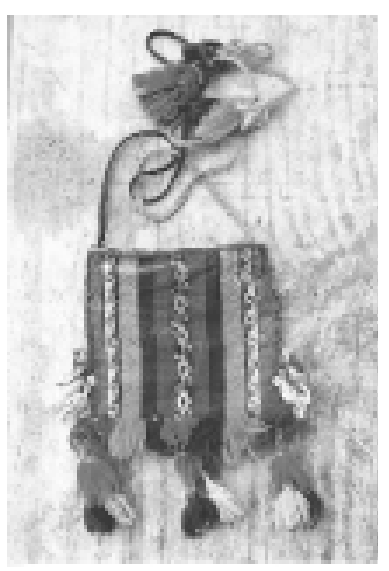


Talega

Bolsa de tamaño mediano de aprox. $28 \times 26 \mathrm{~cm}$ tejida en faz de urdimbre y generalmente en lana de camélido, está conformada por un paño rectangular que se dobla por su mitad. Su diseño mantiene una rigurosa tradición precolombina, basado en listas verticales de diferentes matices en los colores naturales de la fibra. En algunos ejemplares se introducen líneas de color, como también algo de "labor", la que va en la franja central. Este contenedor se emplea para "trajinar" azúcar, harina tostada o mantener semillas, por lo que muchas veces lleva cosido un trenzado pequeño que sirve para cerrarlo con una amarra.

\section{Costal}

Bolsa de grandes dimensiones de aprox. $113 \mathrm{x}$ $68 \mathrm{~cm}$, que se ocupa para guardar grano o transporte de carga; está tejida en faz de urdimbre y con hilado grueso. De un solo paño doblado verticalmente por su mitad, mantiene desde tiempos prehispánicos un patrón la mayoría de las veces simétrico, de listas verticales anchas, las que pueden estar alternadas por listas finas. Generalmente es de lana de oveja en colores naturales, es decir, crudo, café, beige y negro. Algunos escasos ejemplares incorporan en pequeña proporción el rosa fuerte.

\section{Faja}

Prenda que mide aprox. $154 \times 8 \mathrm{~cm}$ tejida en faz de urdimbre, empleando telar de cintura. La variedad de sus dibujos se deriva de los patrones ortogonales de la estructura y su importancia se refleja en que las denominaciones que reciben algunos diseños le entregan dicho nombre a la prenda completa; es así como por ejemplo tenemos la faja "tabla o taula", cuyo diseño presenta filas de pequeños cuadrados logrados por efectos de flotes de la urdimbre, el que tiene antecedentes prehispánicos. La faja es terminada con flecadura torcida o trenzada. La usan aun hombres y mujeres para reforzar la cintura en el esfuerzo del trabajo diario.
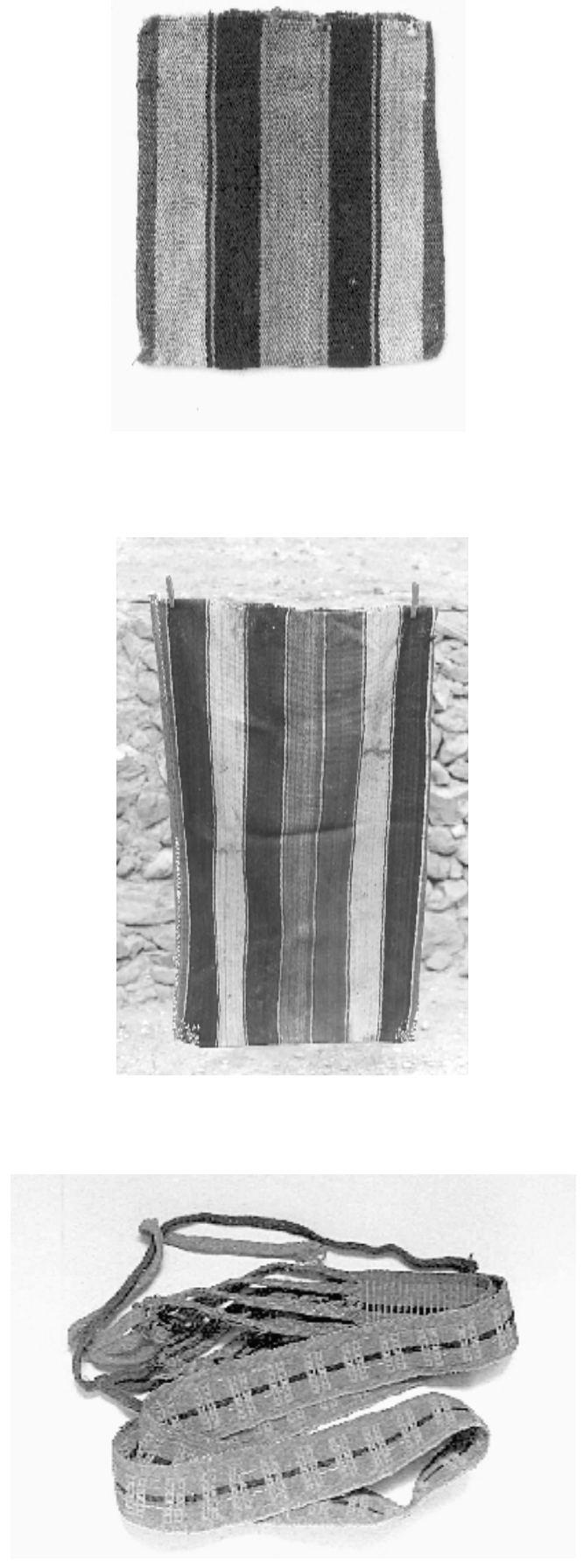


\section{Llijlla}

Prenda de aproximadamente $83 \times 89.5 \mathrm{~cm}$ tejida en faz de urdimbre construido en telar de estacas y compuesto por dos paños unidos en la vertical. En la zona del Salar tienen sus campos en el color natural de la fibra, mientras que en la zona del Loa frecuentemente son teñidas en colores oscuros. Lleva "labor" en la franja central y en las laterales. Antiguamente se tejían con sus cuatro bordes terminados, pero en la actualidad se teje un paño largo, el que se corta por la mitad, terminando el lado cortado con aokipao. Su uso tradicional es para cargar a los niños pequeños, transportar peso, como rebozo y a veces cumple funciones rituales.

\section{Inkuña/Unkuña}

Pequeño textil de uso ceremonial. Está conformado por un solo paño que debe medir un mínimo de $20 \mathrm{~cm}$ x $20 \mathrm{~cm}$ y un máximo de $30 \mathrm{~cm}$ x 30 $\mathrm{cm}$. Tejido en faz de urdimbre en telar de estacas, su diseño es un listado vertical definido por la disposición de la urdimbre. Por su carácter ritual es un textil de acceso reservado y sus indicaciones de tejido y diseño se mantienen muy estrictas, como ser un textil de cuatro orillas. La teje una mujer, ya sea madre, esposa o hermana del yatiri, como obsequio o herencia, o una maestra tejedora por encargo.

\section{Poncho}

Prenda que mide aprox. $180 \mathrm{~cm}$ x $144 \mathrm{~cm}$. Tejida en un denso faz de urdimbre empleando hilado de alpaca o lana de oveja fuertemente torcido. Están confeccionadas a partir de dos paños cosidos en la vertical. Son de un solo color con una franja ancha a ambos lados. Los hay en matices naturales de las fibras y también de colores artificiales fuertes. Terminan con flecos que pueden ser los extremos de la urdimbre o estar tejidos separadamente y cosidos, curvando las esquinas. Existen ponchos especiales para ocasiones rituales, como carnaval o floreo que generalmente son rojos o fucsias y de luto en color negro entero o con franjas laterales de color morado. Es una prenda usada mayoritariamente por los hombres.
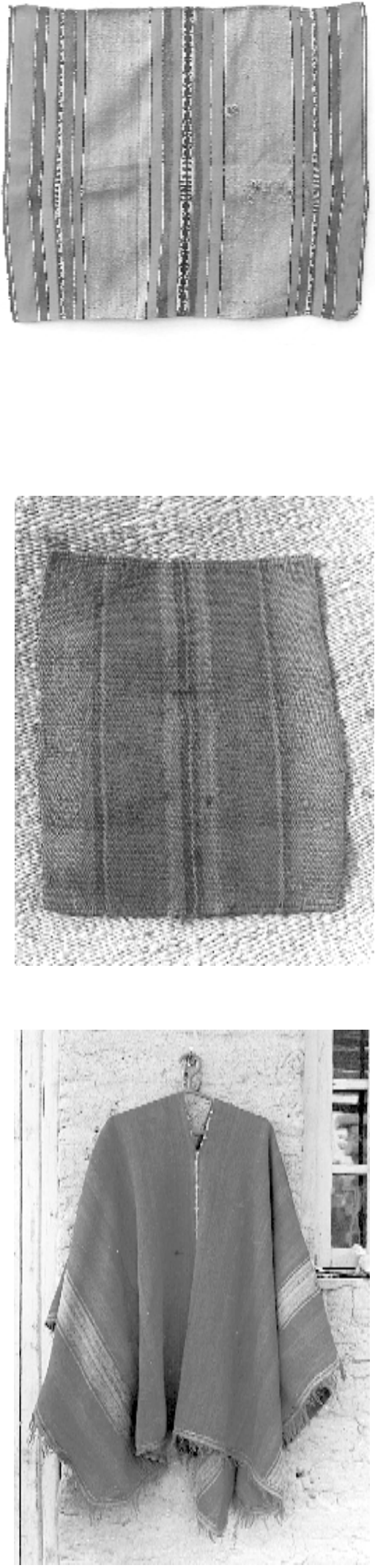
Alforja

Bolsa doble que mide aprox. $94 \mathrm{~cm} \mathrm{x} 35.5 \mathrm{~cm}$. Tejida en faz de urdimbre se confecciona a partir de un paño rectangular que, doblado en sus extremos, forma dos bolsos para transporte de carga. Tejidas en lana de colores naturales y teñidas, algunas bolsas presentan bordados en su cara exterior. Las hay de ceremonia o carnaval, las que pueden tener una abertura en el centro para ponérsela a modo de un poncho, pasándolas por el cuello.

\section{Corte}

Paño de aprox. 90 x $200 \mathrm{~cm}$, para confección de prendas, está tejido en telar español o de pedales, utilizando lana de oveja en colores naturales, crudo-café, crudo-negro o gris-negro. Esta tela tiene diferentes diseños en ligamento plano o sarga. Uno de los más frecuentes tiene un diseño en espiga logrado por ligamento de sarga encontrada, que es llamado "cordellate". Mayoritariamente tejido por los hombres, hoy en día está en vías de extinción.

\section{Frazada}

Cobertor de cama, de aprox. 195 x $140 \mathrm{~cm}$, tejido en faz de trama y con gruesos hilados de lana de oveja. Está conformada a partir de dos paños cosidos en la vertical. Los hilos sobrantes de la urdimbre se introducen hacia el tejido rematando los bordes. Como el patrón de tejido de esta prenda no es tan estricto, ha permitido a las tejedoras desplegar su inmensa creatividad, por lo que se registra una gran variedad clasificable en los siguientes tipos:

a) listados horizontales en colores naturales.

b) campos centrales en blanco, bordes con dibujos geométricos en colores naturales.

c) campos centrales en blanco o negro natural, bordes con dibujos geométricos en colores artificiales.

d) campos centrales en color, bordes con dibujos geométricos en colores artificiales.

e) variaciones de las anteriores con dibujos de pájaros y flores.
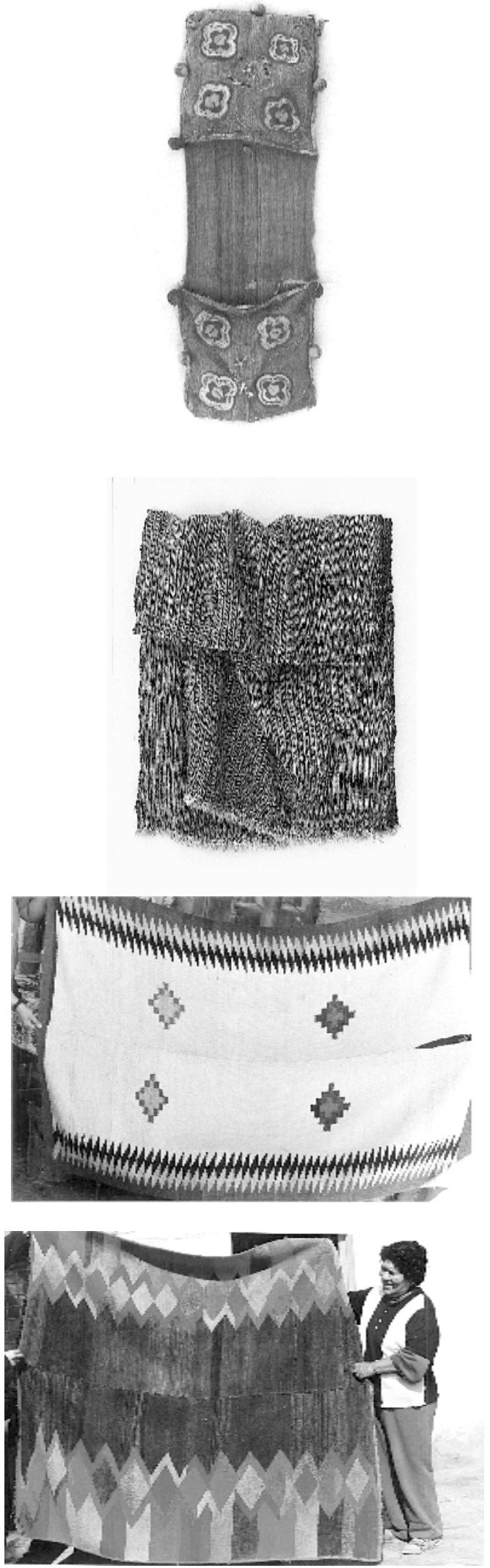
Manta

Cobertor de cama de aprox. 195 x $140 \mathrm{~cm}$. Tejido en faz de urdimbre, se construye de dos paños unidos al centro y cosidos en la vertical. Su diseño es de listados determinados por el colorido de la urdimbre y presenta las siguientes variaciones o tipos:

a) listados en vertical con fondo blanco.

b) listados en vertical con fondo en colores de preferencia derivados del rojo.

c) listados en vertical mezclando colores naturales y artificiales.

d) listados en colores rojos, naranjos y amarillos con terminaciones de flecadura anudada llamada rapacejo.

e) "manta atada", denominación que recibe por su sistema de teñido por reserva, en que los hilos de la urdimbre son atados por grupos, siguiendo un dibujo previamente determinado. Esta urdimbre se sumerge en un baño de tinte, para después del teñido volverla a disponer en el telar y tejerla.

\section{Cubrecama}

Cobertor exterior de la cama tejido en faz de urdimbre o ligamento plano balanceado. Está conformado por dos paños cosidos y presenta una terminación de bordes con flecadura anudada llamada rapacejo, de clara influencia argentina. Los cubrecamas tejidos en ligamento plano presentan bordados preferentemente con temas florales y los realizados en faz de urdimbre, tienen franjas de vistosos colores.

\section{Bajada de cama}

Es una pequeña alfombra de aproximadamente 97 x $53 \mathrm{~cm}$, tejida en telar "español" o de pedales. Realizada en técnica de tapicería puede ser cardada posteriormente. En colores naturales de la fibra de llamas y alpacas, tiene motivos como llamas y cactus, y en la actualidad se encuentran renovados diseños incorporados por sus tejedores. Este textil, introducido en los años ' 60 , fue enseñado por un tejedor de origen peruano. Trabajo realizado generalmente por los hombres, tiene gran aceptación por su rápida comercialización.
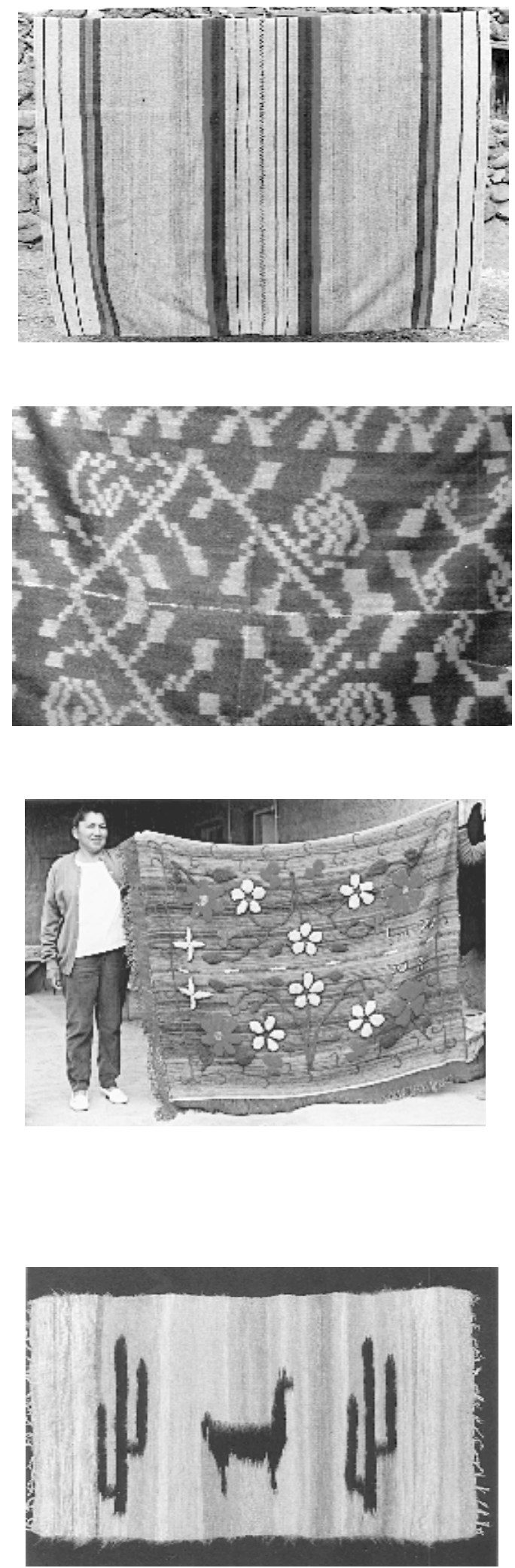
Paño bordado/mantel

Bordados presentes en el sector del Loa, especialmente en Caspana. Trabajados sobre el género de un saco harinero o sobre una tela cruda, presentan diseños de flores y pájaros. Para bordar, se ocupa lana industrial artificial muy delgada y de colores fuertes. Esta técnica fue introducida a fines de los años '70, teniendo mucha aceptación entre sus cultoras; al día de hoy los paños bordados ocupan un lugar de importancia, reemplazando algunas veces a la llijlla, incluso en su función ritual.

\section{Soga}

Gruesa trenza plana de cinco hilos empleada en todo tipo de carga, para amarrar animales, fijar posiciones y otros usos. Tradicionalmente tejida en los colores naturales de la fibra de llamo, por los hombres, para las que también ellos misman el hilado. Presenta diseños sencillos derivados de la alternancia de colores.

\section{Atapollera/Patachurana}

Lazo que usan las mujeres para administrar el largo de la pollera. Trenzado de 16 hebras en colores naturales de alpaca, negro-blanco o café-blanco. El diseño del cordel es resultado del trenzado y está formado por pequeños rombos llamados "ojito de perdiz"; en ambos extremos está terminado en borlas de lana, generalmente industrial, de colores fuertes.
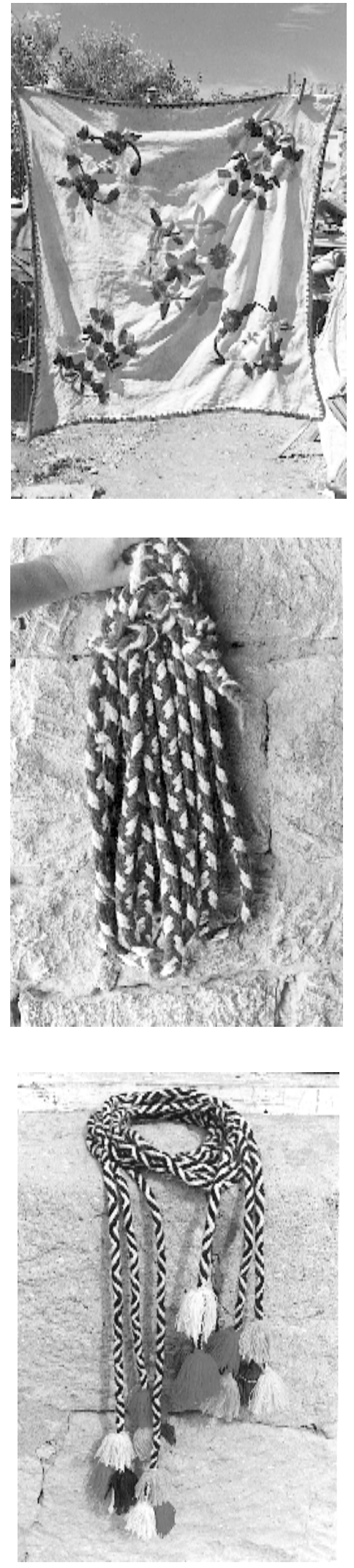
Honda

Instrumento de caza de origen prehispánico. Tiene dos extremos trenzados, formando cordeles delgados y algo más gruesos, con dibujos hacia la pieza central, que está tejida en faz de trama, dejando un ojal. Mide un largo máximo de aproximadamente $200 \mathrm{~cm}$. Son tejidas en colores naturales café-blanco o negro-blanco. Según el número de hilos dispuestos para el trenzado y las distintas combinaciones se logran diseños de zigzag, rombos u ojitos. En la actualidad se utilizan también para arrear el ganado.

\section{Cordel}

Los hay construidos por torsión, formando gruesos cables, o trenzados en cuyo caso dan origen a una gruesa y firme trenza redonda que puede ser de ocho, 16, 32 hilos o más. Se emplea como parte del apero (junto a los frenos) o para las tareas de arreo de animales. Es tejido por los hombres usando de preferencia pelo de llamo. Hay variados diseños formando líneas en espiral, zigzag o rombos, dependiendo de la secuencia de los cruces y el número de hilos utilizados.

\section{Pelero}

Pieza de tejido que mide aprox. 77 x $53 \mathrm{~cm}$. Se realiza en técnica de torzal o encordelado, en telar de bastidor, empleando hilados gruesos y poco torcidos casi siempre en colores naturales de las fibras, produciendo un tejido muy blando, cuya función es proteger el lomo del animal del roce de la montura. Los diseños se obtienen por la alternancia claro-oscuro de las tramas pares y sus desplazamientos en diagonal. Se hacen en juegos de tres piezas de diferente tamaño, las que se sobreponen en el animal de menor a mayor. Son terminados con una pieza angosta de tejido pla-

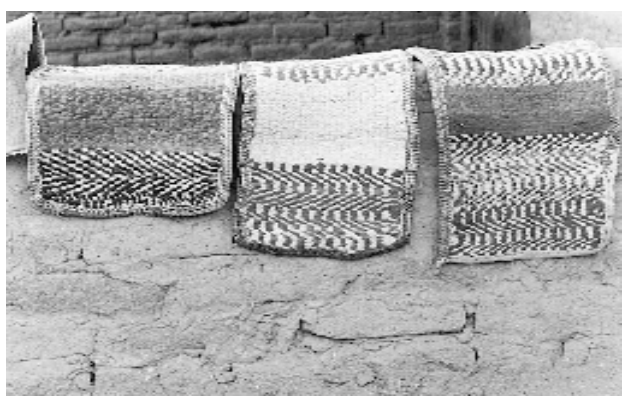
no, la que se cose cubriendo todo el borde. 


\section{Cincha}

Pieza textil de apero, tejida en faz de urdimbre con hilado grueso, es similar a una faja ancha y corta. Se teje en una urdimbre que va montada en una argolla de fierro por uno de sus extremos; termina en un trenzado que se amarra a otra argolla. Su tejido es sencillo, sin ningún dibujo y en el color natural de la lana.

\section{Glosario de términos textiles}

Aguakip/aokipao: técnica de terminación de borde. Combina el tejido de telar en faz de urdimbre con la costura hecha con aguja de coser; a medida que se va tejiendo, la trama se va cosiendo directamente a los bordes de la pieza.

Agujillas/agujetas/espinas: espinas de cardón (Trichocereus atacamensis) empleadas para el tejido de punto.

Awana/telar de estacas/telar de suelo: telar a base de varas o palos horizontales, entre los cuales se tensa la urdimbre, fijando la posición con estacas al suelo.

Bastidor: de fierro o de madera para tejer peleros que antes se tejían en telar de estacas.

Bastonado: diseño del corte (también se llama ojo de perdiz o peinadito).

Cajoncitos: dibujo de orilla en el borde de frazadas. Diseño de triángulos o cuadrados escalonados dispuestos en diagonal formando "cerritos".

Cañarí: fajas para mujeres.

Cañuela: tramero (ovillito).

Caitotachu/caito: palabra de origen aymara, conjunto de hilos.

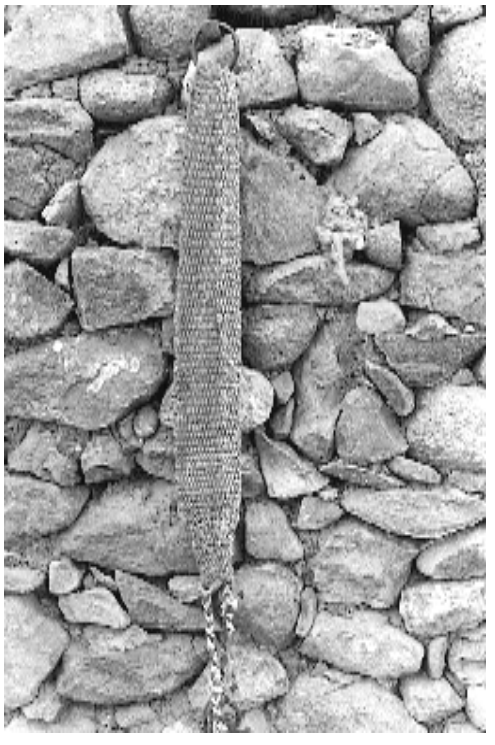

Colmato/kolmátur: en el bastidor del telar de suelo tradicional, los dos travesaños que soportan la urdimbre. En uno de ellos se va enrollando la tela a medida que el tejido avanza. Su tamaño varía según la prenda que hay que tejer.

Costilla: forma de costura en las llijllas, en "triángulo" o "zigzag".

Chacuña: cordón que lleva el sombrero para afirmarlo al cuello.

Chalina: rebozo de uso femenino.

Chomer/chumir: Equivalente de aokipao.

Chorito: dibujo de greca en espiral.

Chulo/chullu/chullo: gorro tejido con palillo; de una sola pieza cubre totalmente la cabeza e incluso el cuello.

Encordelar: técnica para tejer peleros y fajas cañari, torzal.

Guatacuna: lazo para amarrar los llamos cuando se florean o cuando se esquilan.

Guato: cinta tejida para colgante de bolso

Hilar a saya: hilar muy torcido para la urdimbre.

Huso: instrumento para hilar, compuesto de palo $\mathrm{y}$ tortera. 
Illja: atado de pompones y borlas de lana, mayoritariamente de color rojo, que se amarran la viga de una construcción nueva para la protección del lugar.

Ipana: espina para tejido de punto, se saca del cactus chica-chica (cardón chico).

"Isis": diseño como una 'S'.

Kenko: dibujo en zigzag, para faja, chuspas y aplicado ahora a calcetas.

Kotar: efectuar un tipo de costura especial para unir los dos paños de la llijlla.

Labor: nombre que las artesanas le dan a los dibujos logrados por la selección de algunos hilos de la urdimbre.

Labor tijerita: dibujo en forma de ' $\mathrm{X}$ '.

Lacillo: soga delgada.

Liso: pieza del telar de pedales que sirve para seleccionar los hilos de cada calada. Sus agujas pueden ser de lana o metal.

Linko: dibujo en zigzag de atapollera.

Lomillejo/llumillejo/llomillo: trenzado de paja brava. Lo forman siete paquetitos y se usa antes de poner la montura, para que sea más blanda y proteja al animal del peso de la carga; se forra para que éste no se lo coma.

Maneas: amarras para manear los burros, mulas o caballos. Se hace con un tipo de torcido distinto a la soga.

Mataraña: mechas de lana teñidas preferentemente de rojo, morado y verde, las que son atadas a un pequeño palito aguzado. Se compite lanzándolas al techo y deben quedar prendidas entre la paja; son para la protección.

Milunchar: mordentar la lana en aloja de algarrobo durante dos días para después teñirla.

Mismina: huso sin tortera. Palo para torcer la lana firmemente para confeccionar lazos, sogas, hondas y el signo o símbolo.
Mismir: torcer hacia la izquierda; hilado especial para soga y "signo".

Monte: denominación para arbustos y hierbas, tanto medicinales como las que se usan para teñir.

Morral: pequeño bolso.

Muncuna/Llunchu: bozal, tejido como red para tapar el hocico de los animales para que no se coman el pasto mientras se van trasladando de un lugar a otro.

Ojito de perdiz/ojitos: diseño con rombos concéntricos empleado en cordelería y dibujo por urdimbre.

Overito: color jaspeado producido por el uso de un hilado compuesto de dos cabos de diferentes colores.

Pallar: levantar los hilos con la wichuña para hacer labor.

Palta/paltita: cordel plano, nombre derivado de un insecto que tiene una forma aplastada.

Pancitos/campitos: diseños circulares formados por la reserva con amarras en prendas teñidas.

Patanchana: lazo de uso del varón.

Peine de caña: marco con dientes separadores de los hilos, en el telar de pedales; la densidad de los dientes definen la densidad de los hilos de la urdimbre.

Picao: Dibujo de rombos y triángulos llenos, pueden ser en colorido natural de la fibra o en colores muy contrastantes, predominando los rojosfucsia.

Picote: diseño de corte.

Portadas: Denominación para una medida. El peine del telar se mide en el número de portadas (unidad de 12); cada prenda tiene un número definido de portadas, por ejemplo: ocho portadas para la bajada de cama, 12 portadas para un paño de la frazada.

Pulla/Pullo: chal de uso de la mujer. 
Puska: huso, término usado en el Alto Loa.

Rapacejo: fleco.

Reata: soga gruesa para animales.

Riendas: lazo de trenzado en cuero para animales.

Rueca: instrumento mecánico para hilar, de fabricación casera e industrial.

Sainero: palo que se pone entre la illagua y el final de la urdimbre.

Signo/símbolo: prenda de uso ritual que se pone en la cintura del difunto. Consiste en un cordón de aproximadamente $2 \mathrm{~m}$ de largo, realizado con hilado mismeado. Posee nudos (número que varía entre siete y 12 según el entrevistado), los que tienen por objetivo ayudar al muerto a llegar al cielo.

Telar de faja o de cintura: instrumento formado por dos varas o palos que tensan la urdimbre, fijando un extremo con estacas al suelo y el otro con cordeles a la cintura.

Telar de pedales/telar español: de origen europeo, posee peine y lisos accionados por pedales.

Tijne/teine/tujia: gruesa paleta de madera en forma de cuchillón, empleada para apretar el tejido.

Tikallijlla: Llijlla más pequeña con borlitas de colores en las cuatro esquinas donde se ponen las lanas para florear ( $t i k a=$ flores) los animales el 24 de junio, día de San Juan/Inti-Raimi, Año Nuevo.

Talequeao/Talikao: diseño de bordes en frazadas formados por sucesiones de figuras triangulares.

Tortera: peso de madera o piedra para el huso; originalmente era de greda en el alto Loa.

Tulma: lazo con pompones para la trenza del pelo.

Vinasa: instrumento de madera, desgastado en un borde, empleado para apretar el tejido

Wichuña/vichuña/guichuña: instrumento formado a partir de un hueso de llama con cuya punta se seleccionan los hilos de la urdimbre y aprietan los hilos de la trama.

\section{Anexo gráfico}

Entre las piezas textiles tradicionales hay algunas que a nuestro parecer mantienen una continuidad, tanto de uso como técnica y de percepción visual. Es el caso de fajas, chuspas, llijllas y talegas, las que se toman como referencia para presentar un primer estudio de sus diseños. Este ejercicio de seleccionar y ordenar según secuencias visuales, por lo tanto técnicas, los diseños y motivos representados, es un camino que debería llevar al rescate de estos patrones tradicionales, ya que en etapas futuras quisiéramos confrontar con las tejedoras intentando identificar nombres y posibles significados. 


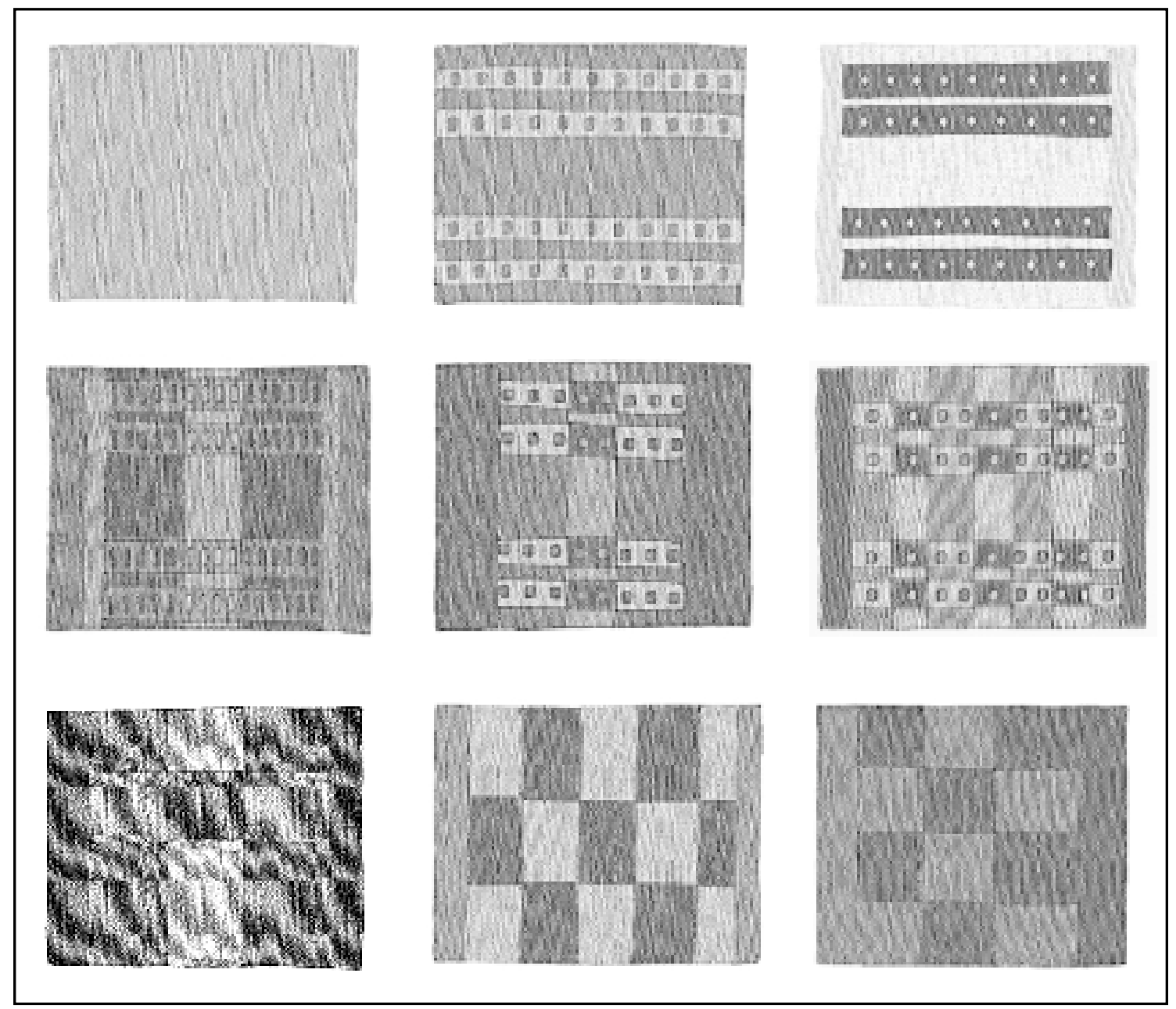

Figura 7. Tipologías de diseños en fajas. Resultan de combinar en diferentes ritmos los flotes de hilos de la urdimbre, para la que se disponen dos capas en colores contrastados, que dan origen a un tejido de doble faz en colores opuestos. Existe preferencia por el rosa y fucsia, combinados entre sí o con naranjas y verdes. La secuencia de imágenes ilustra progresivas modificaciones entre unos diseños y otros, que van desde la faja lisa, la inclusión de cuadraditos formando filas (horizontal), que se complejizan con la superposición de listas verticales, dando lugar a lectura de cruces y damero. 
TEXTILES TRADICIONALES DE LA PUNA ATACAMEÑA

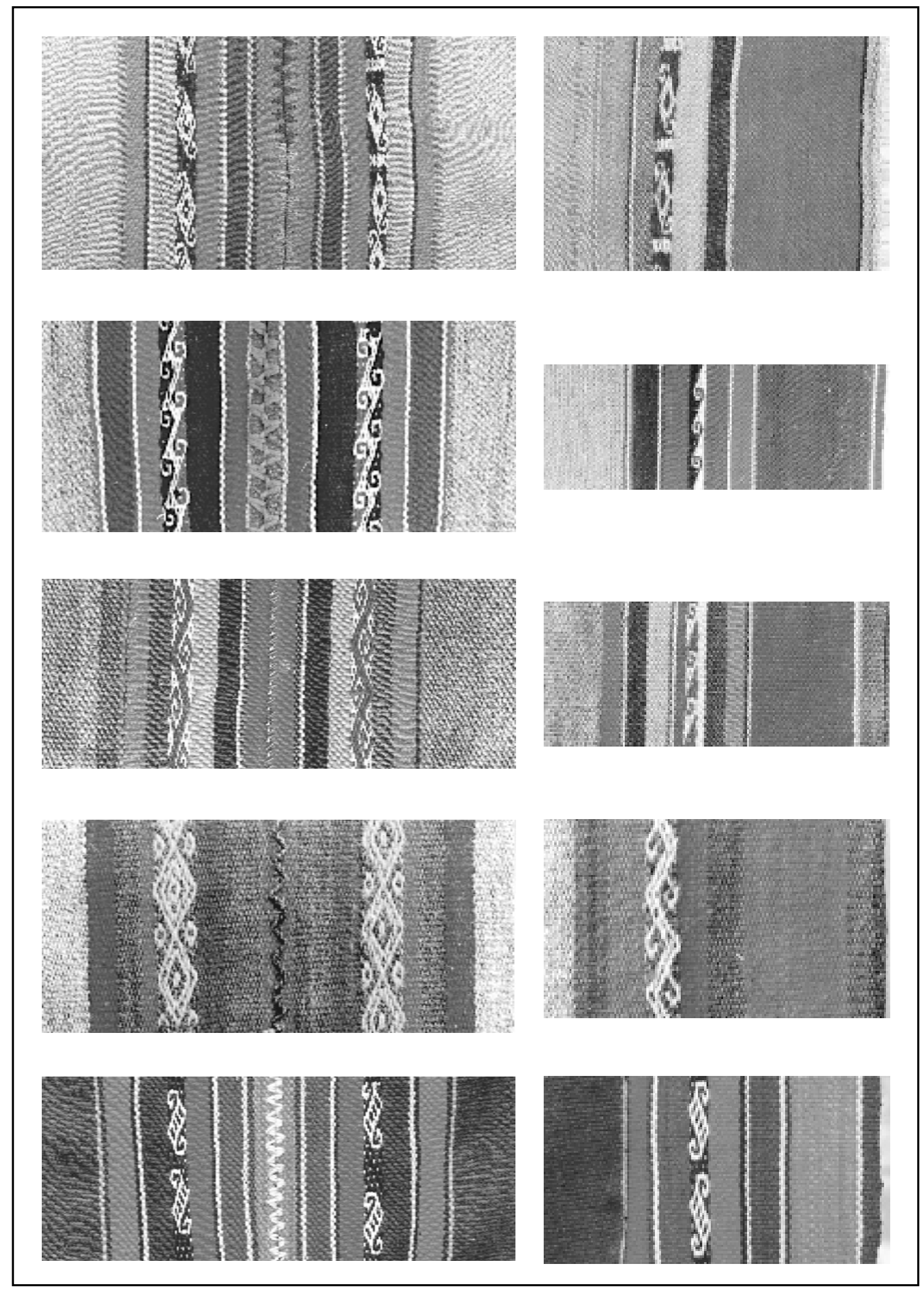

Figura 8. Selección de franjas con labor en llijllas. 


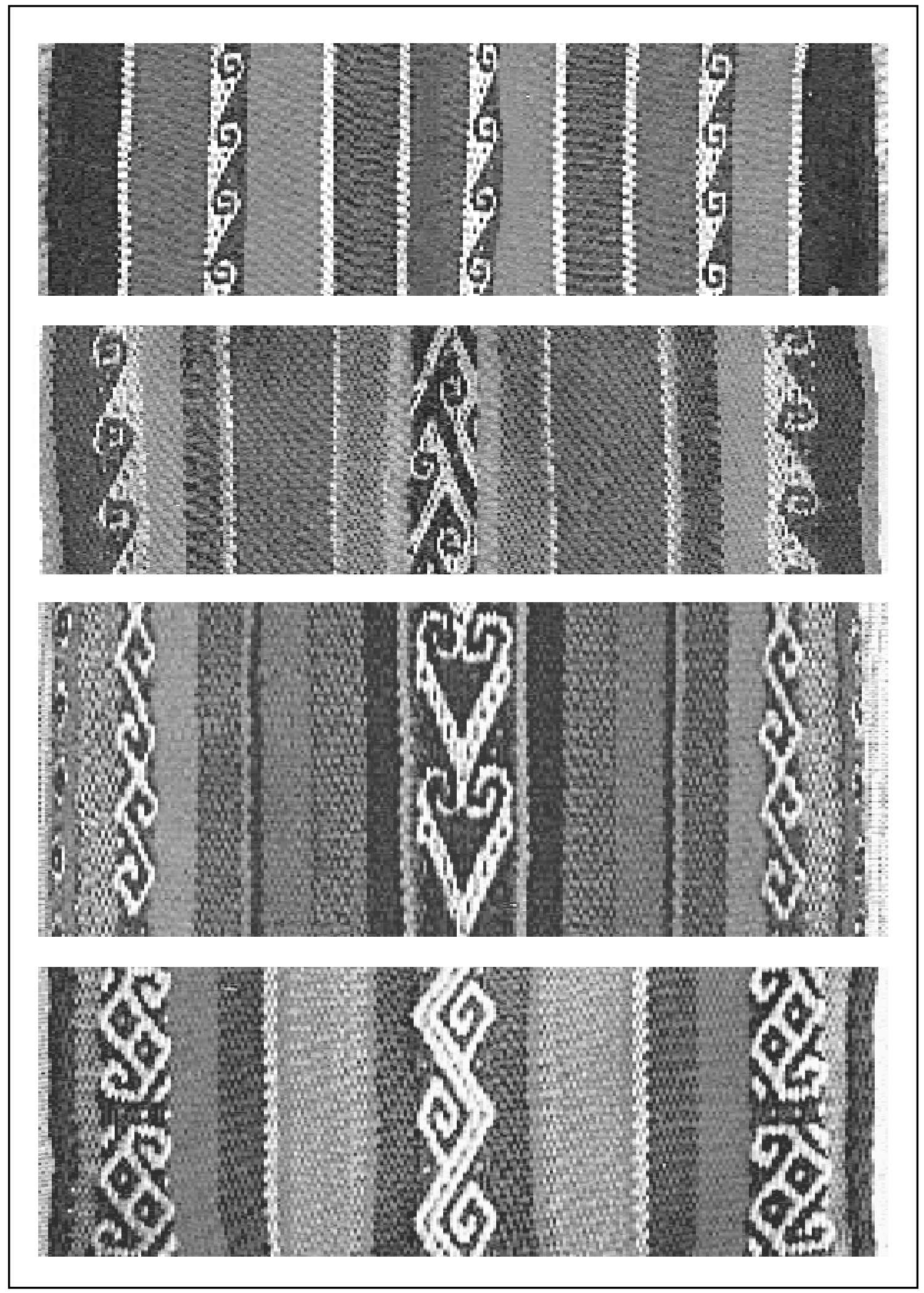

Figura 9. Selección de franjas con labor en chuspas. 

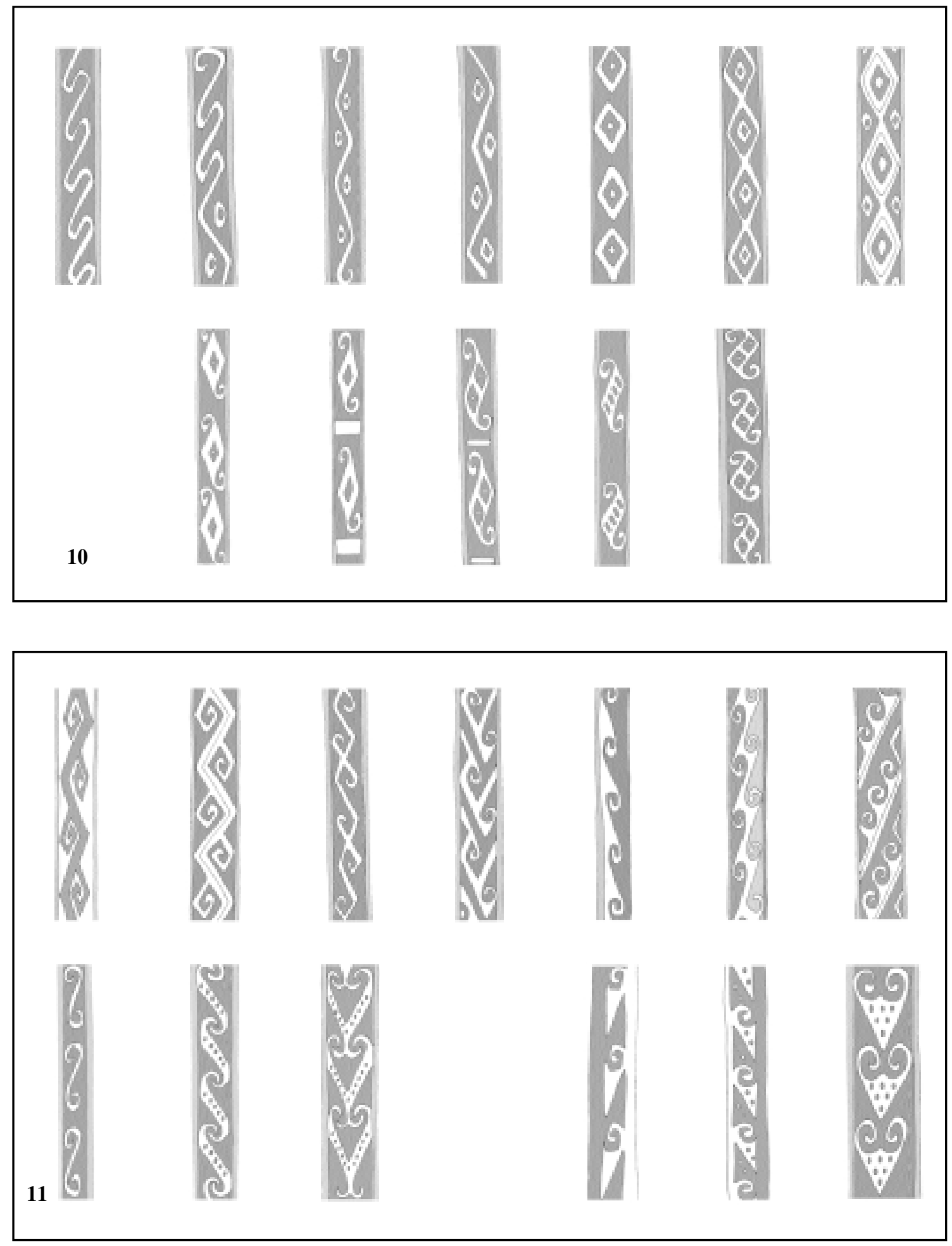

Figuras 10 y 11. "Labores" en llijllas, chuspas y talegas. Las franjas en estas prendas tienen dibujos que son denominados por las tejedoras "labor" y se realizan seleccionando los hilos de la urdimbre según el motivo. Se dispone una urdimbre complementaria generalmente usando color claro, de preferencia blanco, para tejerlos sobre un fondo más oscuro. 
Agradecimientos Queremos agradecer especialmente a las tejedoras atacameñas en las personas de Evangelista Soza de Talabre, Delfina Escalier de Toconce y Berta Cruz de Socaire, quienes con mucha paciencia compartieron sus conocimientos. También entregar nuestro recuerdo a don Eugenio Salvatierra, quien falleciera en octubre del 2000; él como presidente de la comunidad indígena de Cupo acogió y apoyó nuestro trabajo. A Verónica Moreno y Aldo Barrales, nuestros guías y compañeros en terreno. A Loreto Pavez y Alvaro Díaz por su apoyo en diseño gráfico, como también a Isabel Alvarado, quien nos ayudó con la traducción al inglés.

\section{REFERENCIAS CITADAS}

KRUSELL, H., 1976. Artesanos y artesanías de los pueblos precordilleranos de la zona circundante al Salar de Atacama. Estudios Atacameños 4: 131-144, San Pedro de Atacama.

LARRAIN, H.,1990. Apuntes para una geografía artesanal de la II Región de Chile, Ibero-Amerikanisches Archiv, Neue Folge Jehinang 16 Heft 4, pp. 611-636, Colloquium Verlag, Berlin.
LINDBERG, I., 1967. Técnicas en tejidos del Area Andina de la provincia de Antofagasta, Revista de la Universidad del Norte 1: 1-16, Antofagasta.

MOSTNY, G., 1954. Peine: Un pueblo atacameño. Publicación 4, Instituto de Geografía, Facultad de Filosofía, Universidad de Chile, Santiago.

ROLANDI, D., y D. JIMENEZ, 1983-1985. La tejeduría tradicional de la Puna Argentino-Boliviana, Cuadernos del Instituto Nacional de Antropología 10: 205-289, Buenos Aires. 